\title{
Magnetic method used in geothermal reservoirs identification in Kasinan-Songgoriti, East Java, Indonesia
}

\author{
Laily W. Mawarni ${ }^{1}$, Sukir Maryanto ${ }^{2 *}$, Ahmad Nadhir ${ }^{3}$ \\ ${ }^{1}$ Graduate Program of Physics, University of Brawijaya, Malang 65145, Indonesia \\ ${ }^{2}$ Brawijaya Volcanology and Geothermal Research Center, University of Brawijaya, Malang 65145, Indonesia \\ ${ }^{3}$ Instrumentation Laboratory, University of Brawijaya, Malang 65145, Indonesia
}

Corresponding Author Email: sukir@ub.ac.id

https://doi.org/10.18280/eesrj.050402

Received: 7 October 2018

Accepted: 3 December 2018

\section{Keywords:}

magnetic method, reservoir, geothermal,

Kasinan, Songgoriti

\begin{abstract}
The magnetic method had been applied to identify the geothermal reservoirs in KasinanSonggoriti, East Java, Indonesia. The magnetic survey was performed using PPM G-856 and measured on 75 magnetic stations with spacing between each station is 200 meters. The magnetic stations cover of two main hot spring in Kasinan and Songgoriti. The magnetic data were processed by 2D and 3D data modeling. The result of the research showed the range of total magnetic intensity TMI from $31.0 \mathrm{nT}$ to $1207.5 \mathrm{nT}$. The residual anomaly contour map revealed that geothermal reservoir was suspected tend to lie in an area with the low magnetic intensity value around the hot spring and identified as the volcanic breccia. Based on the integrated of 3D inversion and 2D forward modeling data analysis can be obtained the distribution of reservoirs location, depth and the thickness of the geothermal reservoir, the suspected of the presence of secondary structure, the fluid flow pattern from reservoir to the manifestation on the surface, and also Kasinan-Songgoriti geothermal system continuity retrieval.
\end{abstract}

\section{INTRODUCTION}

One of the biggest natural resources in Indonesia is Geothermal resources. Indonesia has about 265 existing geothermal energy potential that located in 138 locations, however only seven geothermal location that have been utilized optimally [1]. Geothermal energy is an attractive choice to provide future electricity needs, another advantage of this energy does not affect pollution to the environment [2]. Geothermal energy was derived from the interaction of rocks and the heat flow on the subsurface [3]. Generally, based on the geological structure the geothermal system in Indonesia consists of five types. Meanwhile, the largest geothermal energy potential are the volcano complexes and grabencaldera volcanic cones [1]. Kasinan and Songgoriti are the areas that have the geothermal potential, it was identified by the presence of the hot springs. Kasinan and Songgoriti areas are located in Quarterly Volcanic deposits which are located between 3 mountains, that is Arjuno-Welirang, Kawi-Butak, and Anjasmara Tua mountain. It is suspected that the three mountains contributed significantly to the geothermal resources in Kasinan and Songgoriti.

Research on the areas that have geothermal energy potential is needed to assess the geothermal system. One of the important stages is identification of the geothermal reservoir. The geothermal reservoir has a very significant influence on the geothermal system. There are numerous geophysical methods that proper used as the geothermal reservoir identification one of which is the magnetic method. Magnetic method is very sensitive toward the heat activity. The magnetic method measures the variation of natural magnetic field intensity value, in this case that has been affected by the heat activity of the geothermal system. This variation was influenced by the magnetization induction process which locally creates positive and negative magnetic field anomalies. For the geological purpose that anomalies become the target of the magnetic survey [4]. The main objective of this magnetic survey is to identify geothermal reservoir includes of the reservoirs location, depth and the thickness of the geothermal reservoir, the suspected of the presence of the secondary structure, the fluid flow pattern from reservoir to the manifestation, and also to identify the continuity between Kasinan and Songgoriti geothermal system.

\section{REGIONAL GEOLOGY OF THE STUDY AREA}

Kasinan and Songgoriti have two main hot spring as the geothermal manifestation. Kasinan hot spring has the coordinate position on $7^{\circ} 52^{\prime} 50.51^{\prime \prime} \mathrm{S}$ and $112^{\circ} 29^{\prime} 47.58^{\prime \prime} \mathrm{E}$ with the number of elevation is $1128 \mathrm{mdpl}$, while Songgoriti hot spring has the coordinate position on $7^{\circ} 52^{\prime} 01.06^{\prime \prime} \mathrm{S}$ and $112^{\circ} 29^{\prime} 33.45^{\prime \prime} \mathrm{E}$ with the elevation is $1002 \mathrm{mdpl}$. Based on the regional geological map, Kasinan and Songgoriti are the areas that located on the foot of the three mountains, that is Mount Arjuno-Welirang, Mount Panderman-Butak-Kawi, and Mount Anjasmara Tua. The result of the previous research, has revealed that Kasinan and songgoriti geothermal system strongly controlled by the structure that oriented on SoutwestNortheast direction. The geothermal system of Kasinan and Songgoriti are formed in Butak-Kawi volcano complex, which is lie on the lane of East Java Quarternary Volcano and flanked by Kendeng lane in the north and South Mountain lane in the south. Tectonic activity and deformations of the Butak-Kawi 
volcano complex have formed the graben zones that formed at the intersection of the Srandil normal fault, Pitrang normal fault, and Cemoro Kandang normal fault which caused of the open fractures to allow the subsurface rocks to have high permeability. The regional geological map for KasinanSonggoriti showed by the figure 1 below [5].

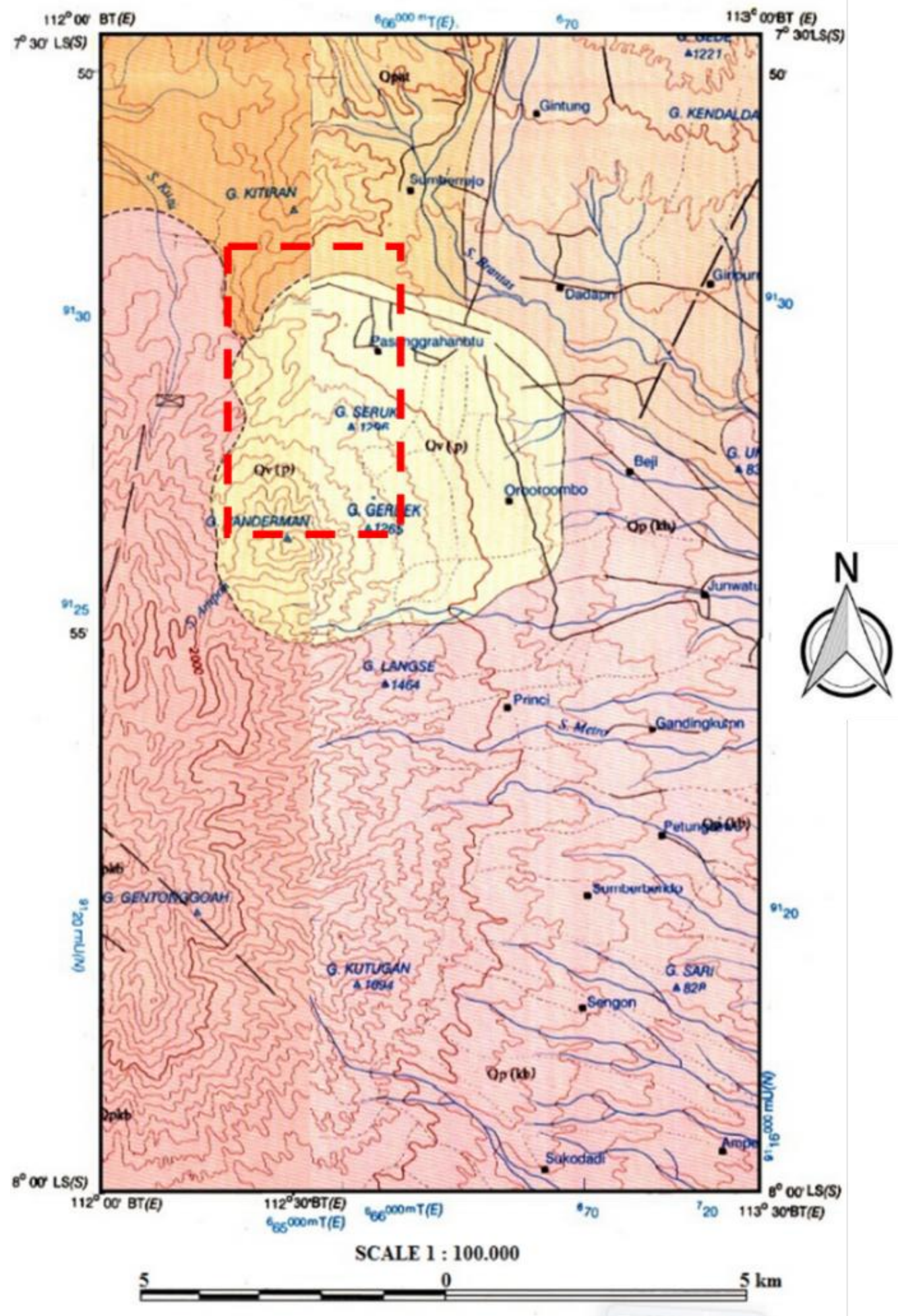

Figure 1. The area with the red dassed line is the research area that lie on Kasinan-Songgoriti area

\section{MAGNETIC METHOD}

\subsection{Magnetic data acquisition}

A preliminary survey was needed before the acquisition. The survey intends to find out the condition of the area that will be used as a research area and used as a consideration when made the survey design for data acquisition. The magnetic data collection was carried out in an area of $2200 \mathrm{X}$ 1400 meters. The magnetic survey was performed using PPM G-856 with $1 \mathrm{nT}$ sensitivity and measured on 75 magnetic stations with the space range between each station is 200 meters it depending on the topography condition. The data acquisition was done by looping method. The magnetic data 
acquisition has obtained the value of total magnetic intensity in the research area. The necessary corrections for the measured magnetic data have been achieved, that were diurnal correction and IGRF correction.

\subsection{Magnetic data processing}

The magnetic data that has been corrected by diurnal and IGRF correction then followed by the transformation of the magnetic field process. The first transformation is the upward continuation. Upward continuation process has resulted the regional anomaly and residual anomaly. These anomalies have been used in the interpretation and delineation of the subsurface structure of the study area. The second transformation is Reduction to Pole (RTP). The information from RTP contour map used as the consideration to determine the position of the slicing data for quantitative interpretation process. The quantitative interpretation has been used to investigate the depths of the subsurface structure like fault and dykes, basaltic intrusions, as well as the basement complex of the considered area. The methods of interpretation are the radially averaged power spectrum, Euler deconvolution, and analytical signal [6]. RTP has changed the inclination towards the vertical direction. RTP as if changing the magnetic field from measurement area into a magnetic field in the magnetic north pole [7]. The purpose of the RTP was localized the areas that have maximum anomalies so they can be located right on the body of the causal source [8]. Some of the filters that used in RTP process consists of Fourier transform that was applied to the data, multiplying by the phase filter, and inverse Fourier transforming the product [9].

\subsection{Magnetic data interpretation}

The interpretation of this study consists of qualitative and quantitative interpretations. Qualitative interpretation based on the pattern reading of the regional and residual anomaly contour maps. The qualitative interpretation has determined the magnetic intensity value below the surface of the data that we have measured. Quantitative interpretation was made by 2D inversions and 3D forward modeling data. Furthermore, the susceptibility value from the reservoir rock can be obtained. Quantitative interpretation was carried out with made the model of the cross section in the area that suspected as the geothermal reservoir location from the contour of the magnetic residual anomaly. Forward modeling was made by making the estimation of the body shape. The main parameter is by looking at the shape of data curve. The parameters are changed by trial and error to get a match between magnetic anomaly curve and modeling curve.

\section{RESULT AND DISCUSSION}

\subsection{Total magnetic intensity}

Figure 2 showed the distribution of the total magnetic intensity of the study area. The intensity ranges from $31.0 \mathrm{nT}$ to $1207.5 \mathrm{nT}$. The difference of these total magnetic intensity value was caused by the differences of the mineral content in the subsurface. The low magnetic anomalies are possible due to the presence of alteration rocks and heat activity. The heat source activity corresponds with demagnetization process toward the rocks in the subsurface that related with the low magnetic intensity value.

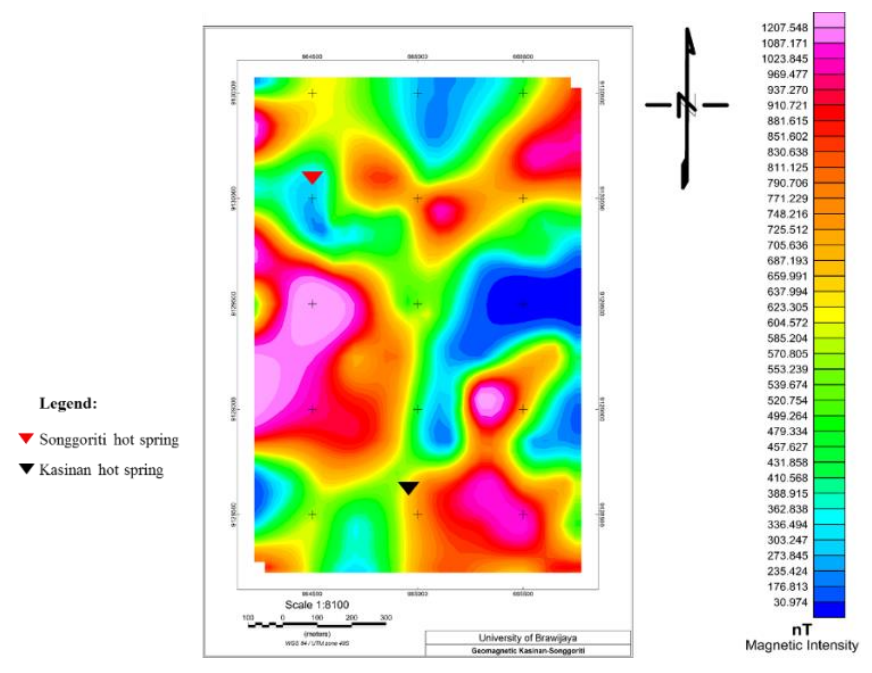

Figure 2. Total magnetic intensity contour map showed the range value for magnetic intensity in study area

\subsection{Separation of regional-residual anomaly}

The purpose of this separation is to get the better resolution of the effect of the broad deeper variations for the regional anomaly from that of the sharper local ones that is residual anomaly as two distinct magnetic maps. The residual countur map that has been filtered by high-pass considered as the most proper and aplicable for the magnetic anomalies interpretation because the resulted of residuals are correlated using the correlation coefficient [6]. The residual countur map showed in figure 3.

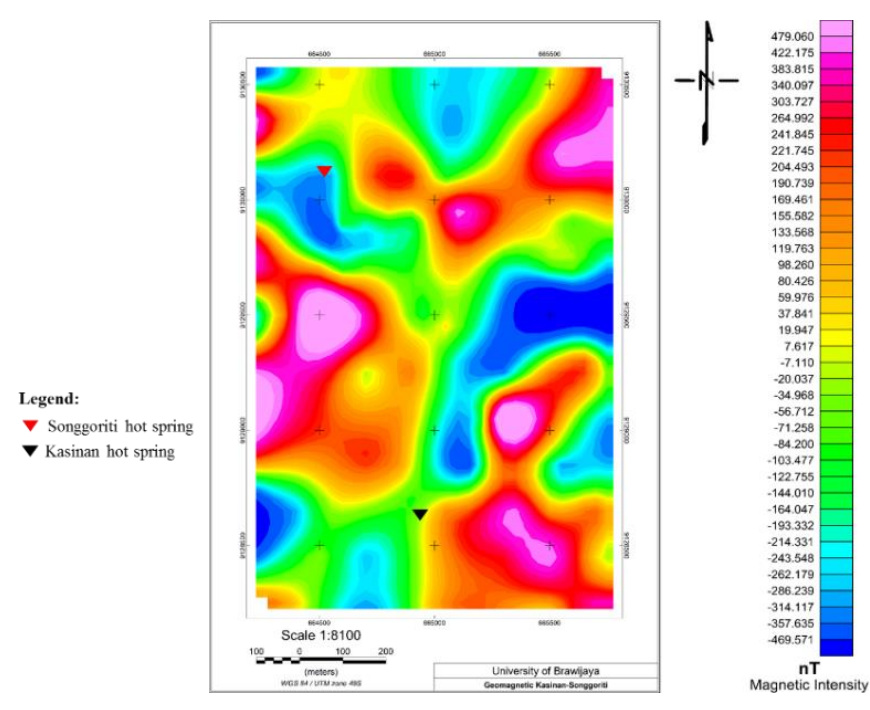

Figure 3. Residual anomaly contour map

Figure 3 revealed that low anomaly zone covered the two of hot spring manifestation. The negative anomalies influence by the existence of the grabens with sediment fill while the positive anomaly can be assumed as the result of intrusion process of high magnetic susceptible material [10]. For geothermal reservoir research, the anomaly that use as the main study is the pattern area with the low value of magnetic intensity. Residual map showed the low magnetic intensity range from $-469.57 \mathrm{nT}$ to $-164.05 \mathrm{nT}$ that oriented at Northwest and East from the map. These value decreases for 
the area around the manifestation. Perhaps the very low magnetic intensity related with the non-magnetic rocks, therefore, it makes a strong assumption that the rocks in the subsurface have undergone of demagnetization process.

\subsection{Reduction to pole}

The aim of RTP process designed in order to change the magnetic survey data from a magnetic dipole transformed into a monopole. The RTP process was indispensable for data interpretation process. Based on the RTP contour map the low magnetic anomaly increasingly gathered around of hot spring both in Kasinan and Songgoriti. This contour has a high anomaly in the middle which separates between two of low magnetic anomaly. The high anomaly was extending that the existence of low magnetic anomaly was associated with geothermal activity. The RTP countur map showed in figure 4 bellow.
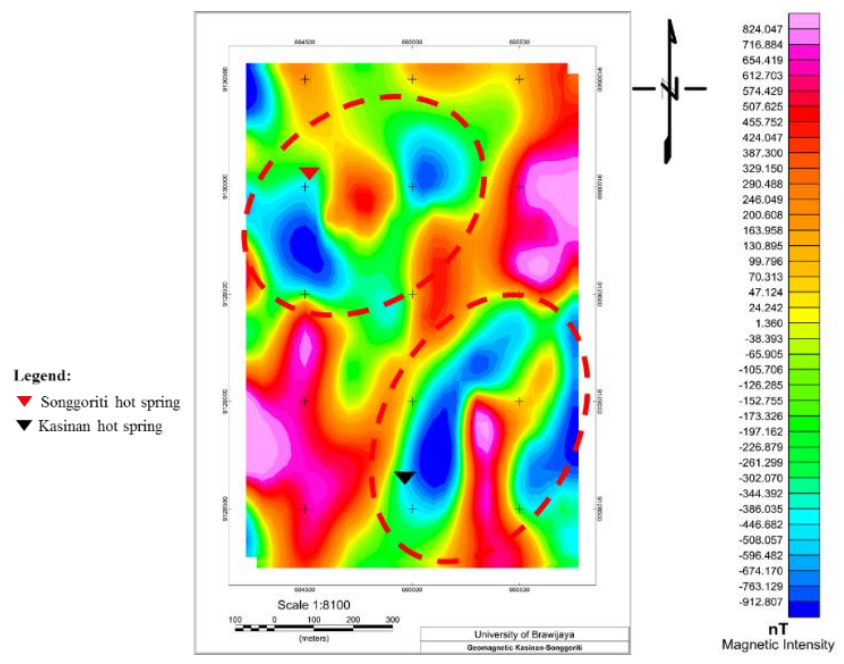

Figure 4. Reduction to Pole contour map

\subsection{Quantitative interpretation}

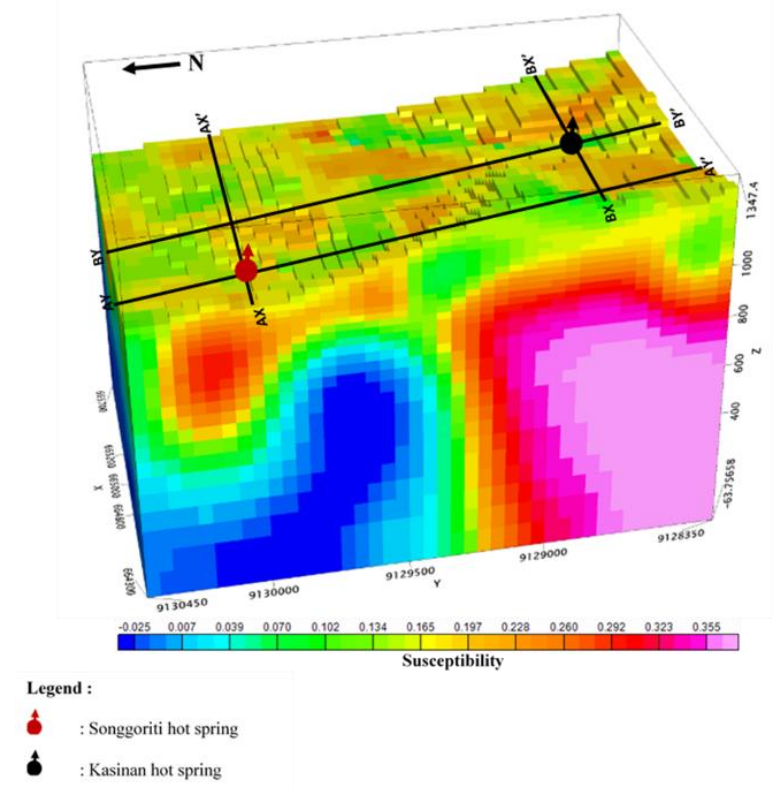

Figure 5. Inversion model based on the result of magnetic method Kasinan-Songgoriti
Inversion modeling was carried out toward magnetic residual anomaly contour map to get the distribution of reservoirs location, depth and the thickness of the geothermal reservoir, to determine the presence of the secondary structure, and also to identify the fluid flow pattern to the surface.

In this study the inversion modeling was consists of two slices in each manifestation point.

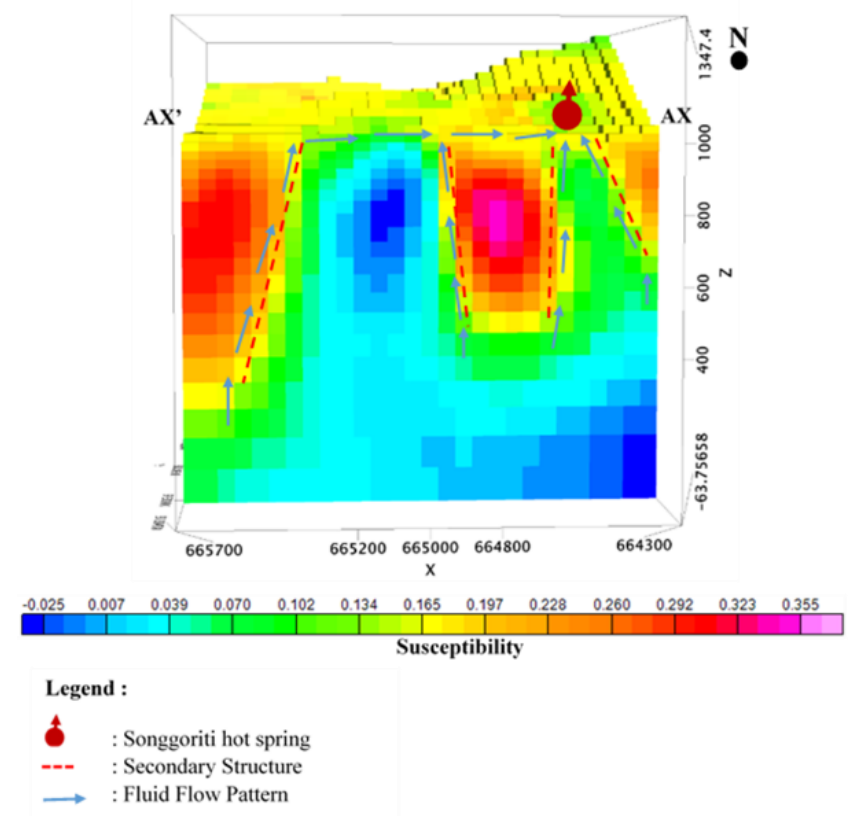

Figure 6. Data slice on the $\mathrm{X}$ axis for Songgoriti geothermal system

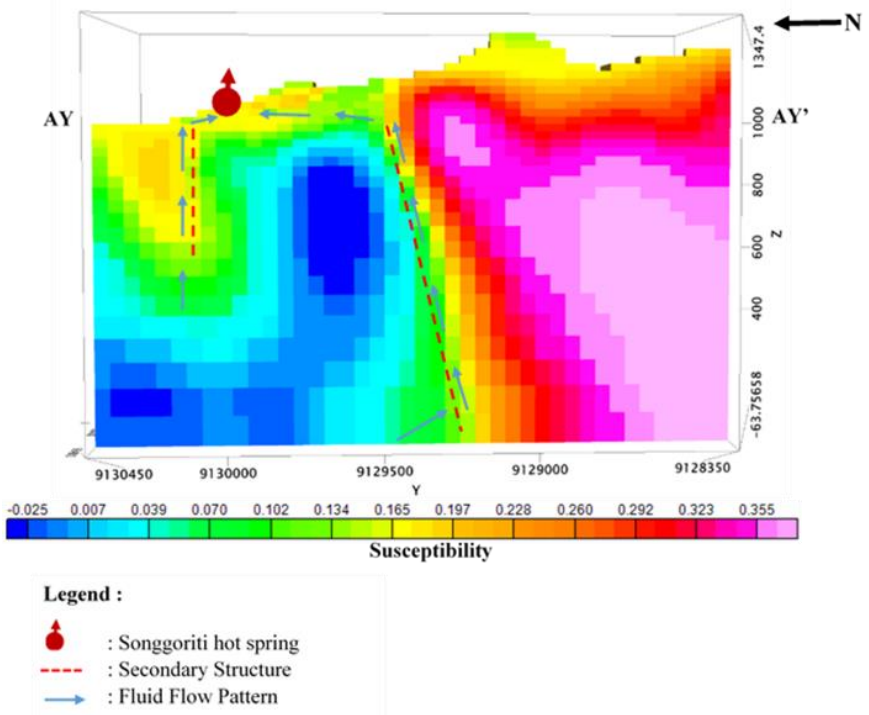

Figure 7. Data slice on the Y axis for Songgoriti geothermal system

AX-AX' is the slicing that oriented on horizontal axis of Songgoriti geothermal manifestation. This slice showed that the manifestation is located above of the area with low suseptibility value. The reservoirs rock was found in dept at 500 meters from the surface, with the thickness is about 1200 meters. Based on the regional geological map area of KasinanSonggoriti was dominated by volcanic breccias, tuff breccias, lava, and tuff [11]. One of the characteristics of the reservoir rock is having a good porosity, therefore by also consider the 
susceptibility value the type of rock that suspected as the reservoir rock in this geothermal system is volcanic breccias. The above of reservoir rock there are kind of rock that assumed as the cap rock. A strongly suspected that the kind of rock that being the cap rock is tuff. That rock was a type of rock that has high impermeability, that means if the geothermal manifestation was located in this area we can be assumed that there are secondary structure that caused the way of the fluid to the surface. This supposition is appropriate with the result of the previous research in this area. In Kasinan-Songgoriti by using the derivative analysis, there was found a structure which controlled the hydrothermal activity in these area [11]. The tentative model of $\mathrm{AX}-\mathrm{AX}$ ' has found the existence of four secondary stuctures.

AY-AY' is the data slice that oriented on vertical axis of Songgoriti geothermal manifestation. The slice used to prove location and kind of the reservoir rock that causes of Songgoriti manifestation. From AY-AY' the thickness of reservoir rock is about 950 meters and located on about 300 meters from the surface. From AY-AY' data slicing has determined the existence of two secondary stuctures that caused of Songgoriti manifestation.

For Kasinan geothermal system the result of the inversion modeling showed below.

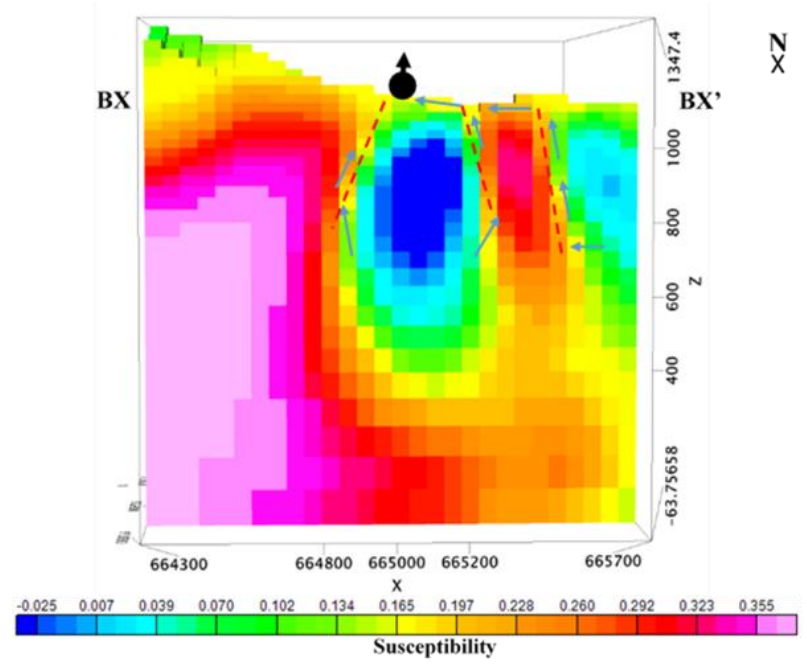

Legend :

: : Kasinan hot spring

$\longrightarrow$ : Secondary Structure

Fluid Flow Pattern

Figure 8. Data slice on the $\mathrm{X}$ axis for Kasinan geothermal system

Kasinan is located in the Southeast of Songgoriti. Based on the Kasinan data slice can be interpreted that the kind of reservoir rock of the Kasinan manifestation is equal with Songgoriti manifestation. The result of the BX-BX' data slice has determined the body with low suseptibility value at shallow depth at 50 meters from the surface with the thickness around 300 meters. Although it has a low susceptibility value, it is probably not the main reservoir of the Kasinan geothermal system. That is thought to be a porous rock that stores the hot fluid from the main reservoir and flows into manifestation. The deeper investigations are carried out by making and reading the pattern of BY-BY' data slice. The result of BY-BY' has determined the body that suspected as the main reservoir rock that still belong of the continuity from Songgoriti geothermal reservoir. The pattern and the existence of secondary structure revealed that the fluid in the Kasinan manifestation might be supplayed by the same reservoir with Songgoriti system. This result is appropriate with the result of the geochemical data analysis. Depending on the $\mathrm{Cl}-\mathrm{Li}-\mathrm{B}$ diagram to find out the origin of the water, it has revealed that the samples of the Kasinan manifestation indicating that the water originates come from the same reservoir with Songgority manifestation. BX-BX' data slice showed the presence of the three secondary stucture while BY-BY' revealed the four existence of secondary structure. BY-BY' has indicated that Kasinan geothermal system comes from one reservoir rock from Songgoriti system. To strengthen this assumption it was confirmed by the result of the data clipping in inversion data model that showed in figure 10. For inversion data clipping, the data that has been choosen were the data with low susceptibility value that interpreted as the part of the heat source and part of the reservoir rock. Based on the figure 10 , the main heat source that is represented by dark blue coluor suspected lie on the Songgororiti geothermal system. The existence of the secondary structures allows the hot fluid from Songgoriti system to flow to the Kasinan geothermal system.

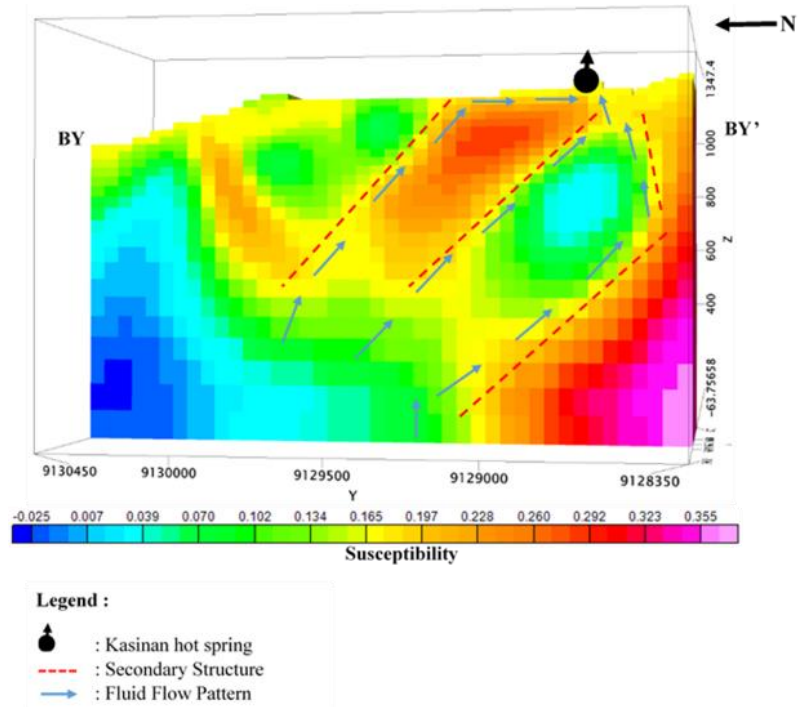

Figure 9. Data slice on the $\mathrm{Y}$ axis for Kasinan geothermal system

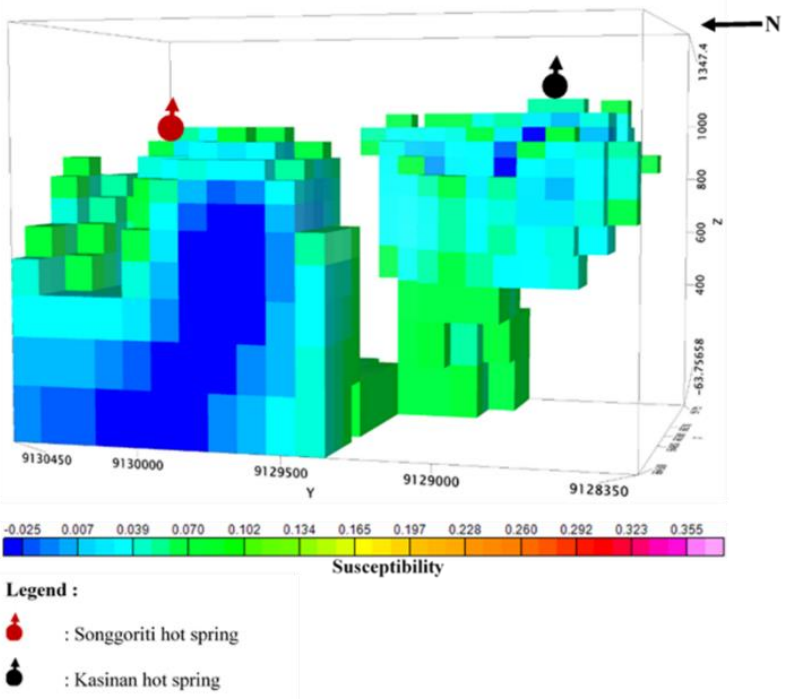

Figure 10. The continuity between Songgoriti and Kasinan geothermal system 
The deeper identification about Kasinan-Songgoriti geothermal reservoir was made by forward modeling that showed in Figure 11. The forward model was made on magnetic residual anomaly contour map with a length of the slice as far as 1.500 meters that connecting Songgoriti manifestation and Kasinan manifestation. The result of the forward modeling showed that the subsurface structur under the Songgoriti manifestation there are a secondary structure that identified as minor fault furthermore there are a buried dyke which indicates that the rock body that it passes has a good porosity and was identified as the reservoir rock. Meanwhile, under Kasinan manifestation the secondary structure that identified as minor fault was also found. Perhaps this minor fault was made the cracks as the way of the fluid to flow to the surface. The most types of rock that can be found in Kasinan-Songgoriti area are tuff, tuff breccia, lava, volcanic breccia and also clay [12].
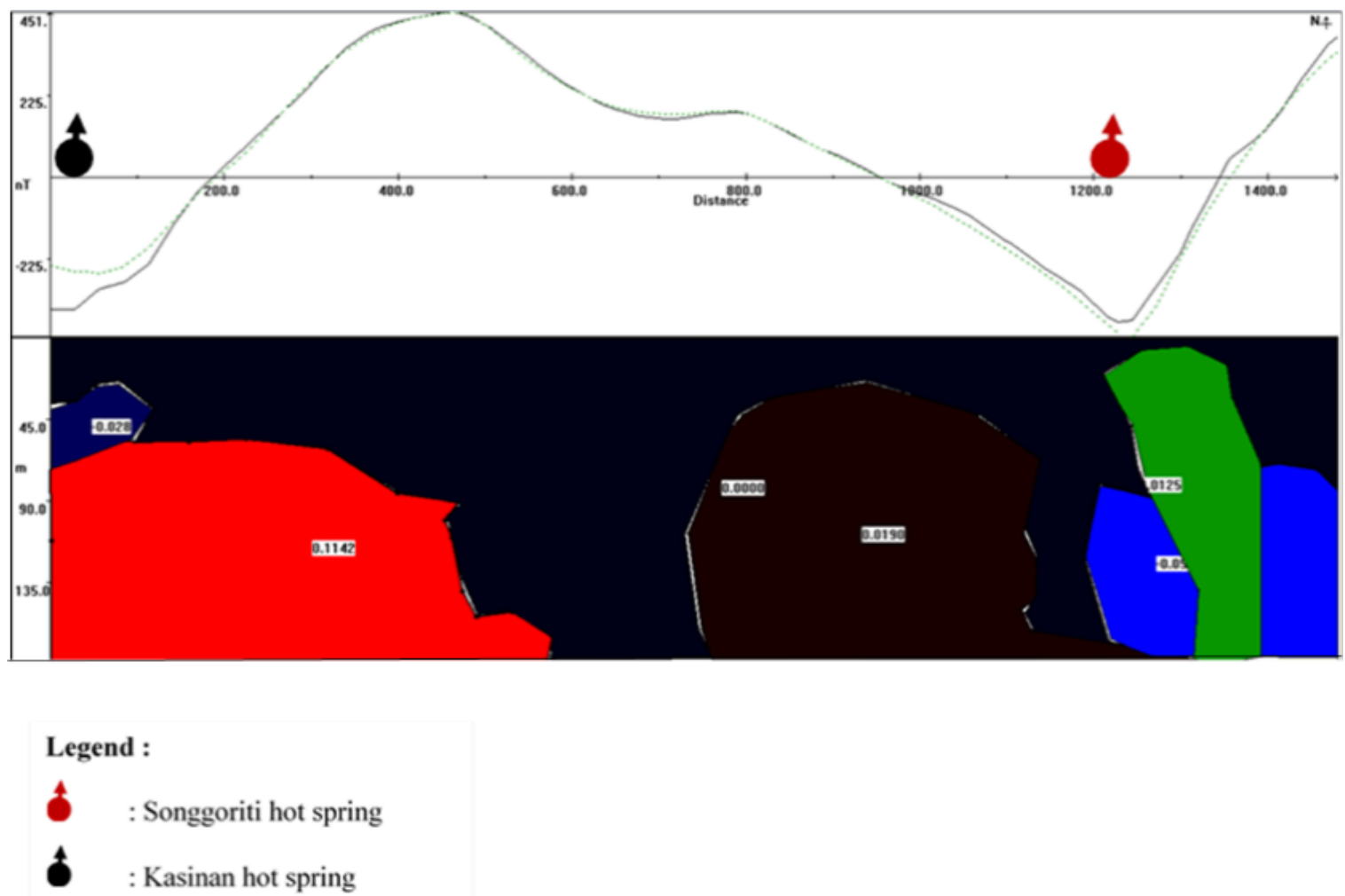

Figure 11. Forward modeling for magnetic anomaly in Kasinan-Songgoriti geothermal system

\section{CONCLUTION}

The magnetic method is capable to identify the geothermal reservoir. The total magnetic intensity TMI from this study have a range from $31.0 \mathrm{nT}$ to $1207.5 \mathrm{nT}$. The geothermal reservoir was suspected tend to lie in an area with the low magnetic intensity value. The tentative model from magnetic residual anomaly revealed the location, depth, and the thickness of the geothermal reservoir. By considering the range of susceptibility value, and also the information from the regional geological map, the type of reservoir rock for Kasinan-Songgoriti geothermal system belongs to igneous rock and was identified as volcano breccia. The result of this study has also revealed the fluid flow pattern from reservoir to the manifestation on the surface. The presence of the secondary structure is a way of the hot fluid to flow to the manifestation. The secondary structure can be identified as a minor fault, intrusion, or cracks. Based on the inversion data modeling, it was indicated that Kasinan geothermal system comes from one reservoir rock with Songgoriti system.

\section{ACKNOWLEDGMENT}

The author wishes to thank to Kasinan-Songgoriti
Geothermal Workshop Team 2017, which help in the data aquisition process, and also to the member of Brawijaya Vulcanology and Geothermal Research Center University of Brawijaya, Indonesia for endless support during the research.

\section{REFERENCES}

[1] Maryanto S, Dewi CN, Syahra V, Rachmansyah A, Foster JH, Nadhir A, Santoso DR. (2017). Magnetotelluric-geochemistry investigations of Blawan Geothermal field, East Java, Indonesia. Geosciences 7(2): 41. http://dx.doi.org/10.3390/geosciences7020041

[2] Ahmadi MH, Ramezanizadeh M, Nazari MA, Lorenzini G, Kumar R. (2018). Applications of nanofluids in geothermal: A review. Mathematical Modelling of Engineering Problems 5(4): 281-285. https://doi.org/10.18280/mmep.050402

[3] Maryanto S. (2018). Microseismicity of Blawan hydrothermal complex, Bondowoso, East Java, Indonesia. J. Phys.: Conf. Ser. 997012019. http://dx.doi.org/10.1088/1742-6596/997/1/012019

[4] Syukri M, Nordiana MM, Saad R, Marwan, Kamaruddin NA. (2014). Magnetic method used in geothermal exploration in Ie-Seu 'Um, Aceh Besar (Indonesia). 
Electron. J. Geotech. Eng. 19: 2149-2157.

[5] Santosa \& Atmawinata. (1992). Geological Map.

[6] El All EA, Khalil A, Rabeh T, Osman S. (2015). Geophysical contribution to evaluate the subsurface structural setting using magnetic and geothermal data in El-Bahariya Oasis, Western Desert, Egypt. NRIAG J. Astron. Geophys 4(2): 236-248.

[7] Blakely RJ. (1996). Potential theory in gravity and magnetic application. Cambridge University Press. Cambridge. United Kingdom.

[8] Juniarti E. (2017). Identification of Reservoar Geothermal at Kawah Wurung-Ijen complex, Bondowoso, east java using magnetic and remote sensing method. Thesis, Brawijaya University, Malang.

[8] Al-Garni MA. (2010). Magnetic survey for delineating subsurface structures and estimating magnetic sources depth. Wadi Fatima, KSA. J. King Saud Univ. - Sci. 22(2): 87-96.

[9] Vincent O. (2014). Ground magnetic survey in Otukpo area benue state Nigeria. Journal of Natural Sciences Research 4(6): 76-82.

[10] Maryanto S. (2018). Preliminary investigation of volcano hosted geothermal area at Kasinan-Songgoriti-Cangar, Batu city, based on gravity-seismic methods. AIP Conference Proceedings 2021, 050010. http://dx.doi.org/10.1063/1.5062760

[11] Nuha DYU, Avisena N. (2012). Modeling of the subsurface structure in songgoriti hot spring, Batu region based on the geomagnetic data. Neutrino 4(2): 178-187. 